\title{
Rapid Diversification and Time Explain Amphibian Richness at Different Scales in the Tropical Andes, Earth's Most Biodiverse Hotspot
}

\author{
Carl R. Hutter, ${ }^{1, \star}$ Shea M. Lambert, ${ }^{2}$ and John J. Wiens ${ }^{2}$ \\ 1. Biodiversity Institute and Department of Ecology and Evolutionary Biology, University of Kansas, Lawrence, Kansas 66045; \\ 2. Department of Ecology and Evolutionary Biology, University of Arizona, Tucson, Arizona 85721 \\ Submitted November 21, 2016; Accepted May 30, 2017; Electronically published October 23, 2017 \\ Online enhancements: appendixes, supplemental tables. Dryad data: http://dx.doi.org/10.5061/dryad.1555n.
}

\begin{abstract}
aвstract: The Tropical Andes make up Earth's most species-rich biodiversity hotspot for both animals and plants. Nevertheless, the ecological and evolutionary processes underlying this extraordinary richness remain uncertain. Here, we examine the processes that generate high richness in the Tropical Andes relative to other regions in South America and across different elevations within the Andes, using frogs as a model system. We combine distributional data, a newly generated time-calibrated phylogeny for 2,318 frog species, and phylogenetic comparative methods to test the relative importance of diversification rates and colonization times for explaining Andean diversity at different scales. At larger scales (among regions and families), we find that faster diversification rates in Andean clades most likely explain high Andean richness. In contrast, at smaller temporal and spatial scales (within family-level clades within the Andes), diversification rates rarely explain richness patterns. Instead, we show that colonization times are important for shaping elevational richness patterns within the Andes, with more species found in habitats colonized earlier. We suggest that these scale-dependent patterns might apply to many other richness gradients. Recognition of this scale dependence may help to reconcile conflicting results among studies of richness patterns across habitats, regions, and organisms.
\end{abstract}

Keywords: amphibians, biogeography, diversification, speciation, species richness, time-for-speciation effect.

\section{Introduction}

The Tropical Andes region in South America is the most species-rich global biodiversity hotspot, having the highest number and density of endemic animal and plant species in the world (Myers et al. 2000). Within the Tropical Andes, species richness often peaks at intermediate elevations (e.g., Rahbek 1997; Kessler et al. 2001; Kattan et al.

\footnotetext{
* Corresponding author; e-mail: carl.hutter@gmail.com. ORCIDs: Hutter, http://orcid.org/0000-0001-6381-6339.

Am. Nat. 2017. Vol. 190, pp. 828-843. (C) 2017 by The University of Chicago. 0003-0147/2017/19006-57392\$15.00. All rights reserved. DOI: $10.1086 / 694319$
}

2004; Hutter et al. 2013). Yet the evolutionary and ecological causes of these two striking patterns remain incompletely understood, despite many studies on diversification of Andean lineages (e.g., Kattan et al. 2004; Hall 2005; Hughes and Eastwood 2006; Weir 2006; Santos et al. 2009; Drummond et al. 2012; Rosser et al. 2012; Hutter et al. 2013; Madriñán et al. 2013; McGuire et al. 2014; Beckman and Witt 2015; De Silva et al. 2015; Chazot et al. 2016).

Two hypotheses have been suggested to explain spatial richness patterns in general (e.g., Wiens 2011), which can help explain the high species richness of the Tropical Andes and their intermediate elevations: the diversification rate hypothesis and the time-for-speciation hypothesis. The diversification rate hypothesis suggests that faster diversification rates (i.e., speciation minus extinction over time) in clades in some regions and habitats can generate higher species richness relative to other regions and habitats. The time-for-speciation hypothesis (i.e., time-for-speciation effect; Stephens and Wiens 2003) proposes that some regions and habitats have higher richness because they were colonized earlier and therefore have had more time for species to accumulate through in situ speciation. The time-forspeciation and diversification rate hypotheses are not mutually exclusive, as regions and habitats may be species rich because they are both colonized earlier and promote higher diversification rates (e.g., Smith et al. 2007).

A more specific explanation for high Andean richness is the species attractor hypothesis, which proposes that higher dispersal and colonization rates into the Andes from adjacent lowland regions generate the high species richness of the Andes (Beckman and Witt 2015; Chazot et al. 2016). However, it would be difficult to explain the higher richness of the Andes based only on dispersal from adjacent lowlands. If all lowland species simply dispersed into the highlands, richness would be equal across elevations, not higher in the Andes, and there would be no Andean endemics. 
Many studies have suggested that diversification rates are accelerated in Andean lineages (e.g., Kattan et al. 2004; Hall 2005; Hughes and Eastwood 2006; Weir 2006; Rosser et al. 2012; Madriñán et al. 2013; Beckman and Witt 2015; De Silva et al. 2015). However, only one study has explicitly addressed the diversification rate and time-for-speciation hypotheses in explaining the high midelevation richness of the Andes. This study showed that time rather than diversification rates explained this hump-shaped elevational richness pattern in glassfrogs (Centrolenidae; Hutter et al. 2013). Other studies have found indirect evidence for the time-for-speciation hypothesis in Andean clades but without directly linking this evidence to richness patterns (e.g., colonization of lowlands from Andean ancestors; Elias et al. 2009; Santos et al. 2009). Similarly, Chazot et al. (2016) discussed the diversification rate and time-for-speciation hypotheses for a group of predominantly Andean butterflies but did not directly relate their results to richness patterns among elevations in the Andes or among South American biogeographic regions. Overall, direct tests of both of these hypotheses for Andean species richness are still limited, especially across multiple clades and different phylogenetic and geographic scales.

Many ecological and evolutionary factors may influence species richness patterns, but these factors must act on speciation, extinction, or dispersal in order to directly change species numbers (Ricklefs 1987). Therefore, these other factors likely act through their impact on diversification and dispersal (e.g., Wiens 2011; Pontarp and Wiens 2017). For example, various mechanisms have been proposed (but not directly tested) to explain increased diversification rates in the Andes. An important hypothesis is that speciation was recently accelerated by habitat heterogeneity and range fragmentation related to rapid geological and climatic changes caused by the rapid Andean uplift (e.g., in birds: Weir 2006; in butterflies: Hall 2005; Rosser et al. 2012; De Silva et al. 2015; in frogs: Santos et al. 2009; in plants: Hughes and Eastwood 2006; Drummond et al. 2012). Geological evidence suggests that the Andean uplift began in the late Eocene, 40 million years ago (Graham 2009), with the formation of moderate elevation uplands $(\sim 1,000-1,500 \mathrm{~m})$. The Andean uplift then accelerated more recently, with the majority of the Tropical Andes rising an additional 1,500-2,500 $\mathrm{m}$ within the past 10 million years (Garzione et al. 2008, 2014; Parra et al. 2009; Bershaw et al. 2010; Hoorn et al. 2010). Speciation might be related to changes in elevational distributions of lineages and concomitant shifts in climatic regimes. Adaptation to different climates may form a strong barrier to gene flow between incipient species (speciation through climatic-niche divergence; e.g., Moritz et al. 2000; Hua and Wiens 2013). Conversely, speciation might occur among populations that inhabit similar elevational zones and climatic regimes, with geographic iso- lation and allopatric speciation initiated by changing climate that fragments habitats (refugial speciation or speciation via niche conservatism; Moritz et al. 2000; Hua and Wiens 2013; Hutter et al. 2013). Past studies have shown conflicting evidence for these mechanisms in Andean organisms, with support for climatic niche divergence driving rapid diversification in salamanders (Kozak and Wiens 2010a) but not frogs (Hutter et al. 2013).

In this study, we use phylogenetic methods to investigate the evolutionary and ecological causes of amphibian richness in the Tropical Andes, both across elevations and relative to other biogeographic regions in South America. The Andes have twice the amphibian richness of the entire Amazonian lowland rain forest (fig. 1), with more endemic frog species than any other region in the world (Duellman 1999; Myers et al. 2000). We focus on the clade Hyloidea, which contains $>50 \%$ of frog species globally, $95 \%$ of extant South American frog species, and $290 \%$ of South American amphibians (AmphibiaWeb 2016). Hyloidea includes many well-known frog families, such as true toads (Bufonidae), glassfrogs (Centrolenidae), poison frogs (Dendrobatidae), and treefrogs (Hylidae). Our study moves beyond our previous work on glassfrogs (Hutter et al. 2013) by including multiple clades and multiple regions (not just within the Andes), allowing us to address whether and how the causes of richness patterns change across scales.

We estimate the largest time-calibrated phylogeny for hyloid frogs to date (2,318 species; fig. 2) and use phylogenetic methods to test the diversification rate and time-forspeciation hypotheses. We estimate diversification rates across the tree and test for significant increases in Andean lineages. We then test for positive relationships between species richness and diversification rates in different regions and elevations. We also test for positive relationships between richness and colonization times of different biogeographic regions (and elevational zones). Finally, we present the first large-scale test of the hypothesis that increased speciation in the Andes is associated with higher rates of change in elevational distributions among species within clades.

\section{Material and Methods}

Time-Calibrated Phylogeny

Detailed methods for estimating the phylogeny are provided in appendix A (apps. A-E are available online) and are briefly described here. Hyloidea contains 3,571 described species, of which 2,488 species and all 19 hyloid families occur in South America (AmphibiaWeb 2016). We estimated a timecalibrated phylogeny for 2,318 species of Hyloidea (including 1,594 South American species, 64\%) and 14 outgroup taxa. We used published hyloid molecular data from Gen- 


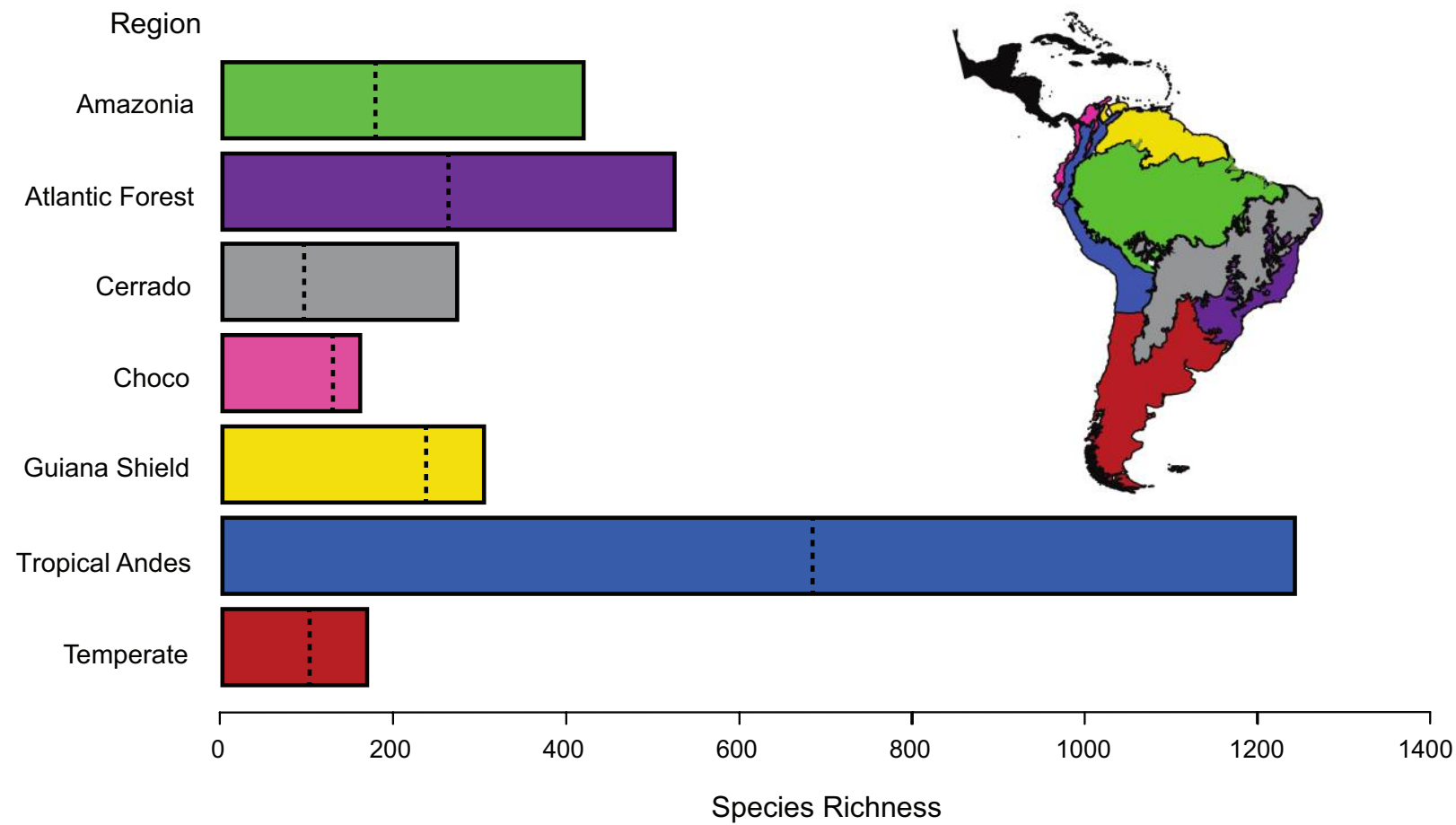

Figure 1: Species richness patterns of hyloid frogs for biogeographic regions within South America. Hyloid frogs include 95\% of extant South American frog species and $\sim 90 \%$ of South American amphibians. Regions are delimited based largely on Duellman (1999). The dotted line within each colored bar represents the number of species included in the phylogeny for that region. Regions outside South America are shown in black.

Bank (stopping August 2014; see table S1 [tables S1-S3, A1, A2, C1-C5, D1-D5, E1-E3 are available online] for GenBank accession numbers; all supplemental tables are also available from the Dryad Digital Repository: http://dx.doi .org/10.5061/dryad.1555n [Hutter et al. 2017]). We assessed each locus to ensure that it contained no contaminated sequences and that sequences corresponded to the correct genus/species (for excluded sequences and corrections, see table S2). Compared to a relatively recent large-scale study including 1,537 hyloid species (Pyron 2014), we increased the number of described hyloid species by $>25 \%$ to 1,950 described species (55\% of Hyloidea, excluding undescribed species). We increased sampling further by including an additional 368 well-supported undescribed species to help account for cryptic diversity.

We estimated a relaxed-clock, time-calibrated phylogeny (fig. 2) using a backbone approach, similar to Jetz et al. (2012). Specifically, we estimated a time-calibrated backbone tree based on a reduced sampling of 158 relatively complete taxa and eight fossil constraints, estimated separate ultrametric trees within each family, and then combined the backbone and family-level trees to generate the overall phylogeny of 2,318 species. We estimated the back- bone phylogeny in BEAST (ver. 1.8; Drummond et al. 2012), using a supermatrix of 13 nuclear and 7 mitochondrial markers. The backbone tree included one species per genus (158 genera with 14 outgroups). The percent completeness of species in the data matrix (i.e., percentage of nonmissing data cells) for each family-level analysis ranged from $27 \%$ to $70 \%$ (mean across all included species in each family) and was $54.3 \%$ for the backbone analysis. These levels of missing data need not be problematic for divergence time and topology estimation with BEAST (Zheng and Wiens 2015). The mean alignment length for nonmissing data across all family-level alignments was 3,705.1 $\pm 2,721.2$ base pairs (range: $259-15,084$ ) with a mean of $5.2 \pm 3.8$ (range: $1-19$ ) genes included per species. The mean alignment length for nonmissing data in the backbone alignment was 7,411.5 \pm 2,923.6 (range: $1,178-15,084$ ) with a mean of $10.3 \pm 3.9$ (range: 2-19) genes per species (see app. A for sampling summary).

We chose eight well-justified primary fossil calibrations to establish minimum ages of extant clades, generally following the criteria suggested by Parham et al. (2012; see app. A for details). When a fossil taxon could be confidently assigned to an extant clade (e.g., a genus) but was of uncer- 


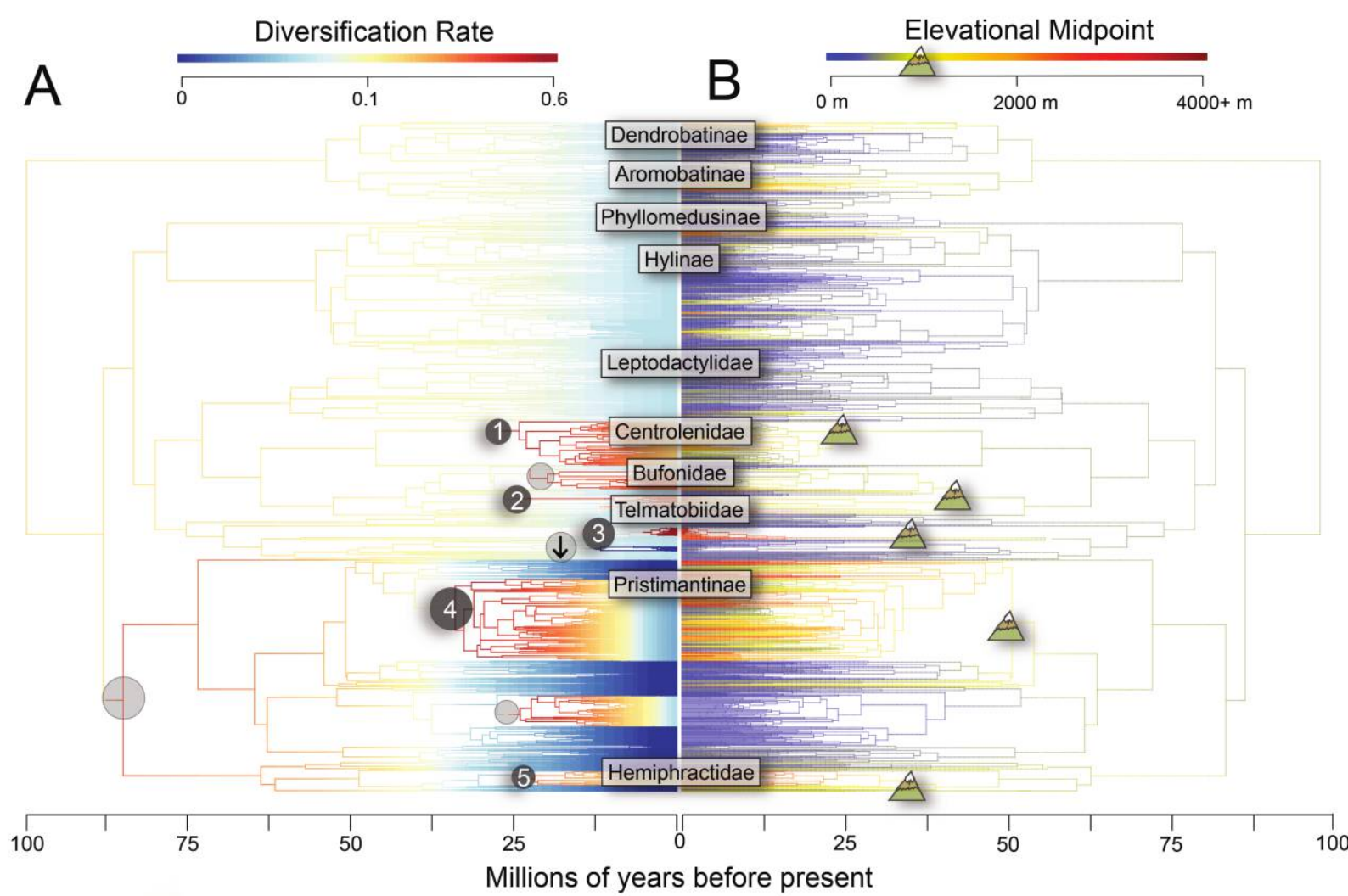

(1)

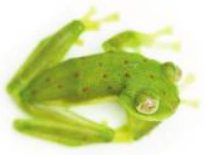

(2)

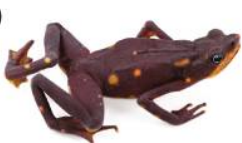

(3)

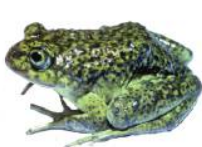

(4)

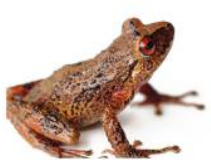

(5)

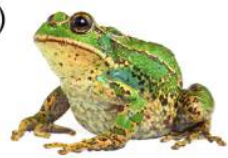

Figure 2: Phylogeny, estimated divergence times, diversification rates, and ancestral elevational distributions for 2,318 species of hyloid frogs. $A$, Diversification rate regimes (and rate changes through time) plotted on the phylogeny. $B$, The same tree, with colored branches showing the general elevational distributions for reconstructed nodes for illustrative purposes (analyses are based on reconstructions of continuous trait values). In $A$, the gray circles are significant diversification rate shifts and are sized according to their marginal probability; those with numbers correspond to Andean clades. The five numbered pictures below the trees show representative species from these five major Andean clades. The down arrow shift represents a diversification slowdown in Cycloramphidae. In $B$, the mountain symbol indicates major Andean colonization events $(>900 \mathrm{~m})$. The 10 family-level clades used for downstream analyses on the phylogeny are labeled. Confidence intervals on divergence times and posterior probabilities of clades are provided in appendix A. Photo credits: (1) Nymphargus grandisonae and (4) Pristimantis pteridophilus by C. R. Hutter; (2) Atelopus longirostris and (5) Gastrotheca pseustes by Alejandro Arteaga; and (3) Telmatobius pisanoi by William E. Duellman.

tain phylogenetic placement within that clade, we used the fossil to provide a minimum age for the split between that clade and its sister taxon (stem group age). Following standard practice, calibrations were set to a lognormal distribution because a fossil can establish the minimum age of a clade but the clade could be substantially older (see app. A).

We estimated divergence times separately within strongly supported families (sensu Pyron and Wiens 2011) using all sampled species in each family. We rescaled the root age of each family tree to match the backbone tree such that the complete tree remained ultrametric. Finally, we grafted these family trees onto the backbone tree. Using this strategy, between-family divergence times were based on the fossil-calibrated backbone analysis, and within-family divergence times were based on uncalibrated relaxed-clock analyses that maximized taxon sampling. All alignments and trees have also been deposited in Dryad: http://dx.doi .org/10.5061/dryad.1555n (Hutter et al. 2017).

The estimated tree was largely congruent with other recent, large-scale hypotheses of hyloid relationships (e.g., 
Pyron and Wiens 2011; Pyron 2014). The main difference involved the position of Dendrobatidae. Therefore, we also performed phylogeny-based comparative analyses on a second tree, which was constrained to provide a closer match to previous hypotheses regarding the placement of Dendrobatidae (see "Supplemental Appendix," available online, for detailed methods and results). Results were very similar between trees, and all analyses reported here are from the unconstrained tree. This comparison also suggests that further changes in the phylogeny should have limited impact on our phylogeny-based conclusions.

\section{Quantifying Richness Patterns}

We compiled species geographic distributions and elevational ranges from the Global Amphibian Assessment (GAA) of the International Union for Conservation of Nature (IUCN 2014) to quantify richness for (1) major biogeographic regions and (2) elevational zones in the Andes (distributional data included as table S3). We assembled data for species not present in the GAA from the original species descriptions (available in AmphibiaWeb 2016). We also performed separate analyses of elevational richness patterns within 10 clades (fig. 2; table 1) that collectively included $91 \%$ of South American hyloid species (app. B). These clades are distributed primarily in the Andes or South American lowlands and not in non-Andean highland regions (e.g., high elevations of the Atlantic Forest region and the tepuis of the Guiana Shield). We defined species occurring from 0-900 $\mathrm{m}$ as lowland, from $800-6,000 \mathrm{~m}$ as Andean, and those simultaneously occurring $<800 \mathrm{~m}$ and $>900 \mathrm{~m}$ as both. These limits were based on the average lower limit of Andean montane forests (Hooghiemstra et al. 2006; Hoorn et al. 2010). The $100-\mathrm{m}$ overlap was added to prevent coding species as both due to extremes in their distributions. Based on our data, no species are distributed exclusively between 800 and $900 \mathrm{~m}$.

Seven standard biogeographic regions within South America were used: Amazonia, Tropical Andes, Atlantic Forest, Choco, Cerrado (including Caatinga), Guiana Shield, and temperate South America (fig. 1). These regions largely followed Duellman (1999), who identified regions based on patterns of frog endemism. We acknowledge that seven regions may not be a large sample size for these analyses, but our regression results (see below) show that there is sufficient power to obtain significant results with only six regions. Furthermore, these seven regions already encompassed all of South America and so it would be impossible to increase the sample size without subdividing one or more regions. We do not think that there is strong bio-

Table 1: Summary of diversity, distribution, and ages of hyloid frog clades used to test the time-for-speciation and diversification rate hypotheses at smaller phylogenetic scales

\begin{tabular}{|c|c|c|c|c|c|c|c|}
\hline \multirow[b]{2}{*}{ Clade } & \multirow{2}{*}{$\begin{array}{c}\text { No. } \\
\text { genera }\end{array}$} & \multirow{2}{*}{$\begin{array}{l}\text { Species total } \\
\text { (sampled) }\end{array}$} & \multicolumn{3}{|c|}{ Elevational range $(\mathrm{m})$} & \multirow[b]{2}{*}{ Majority region } & \multirow{2}{*}{$\begin{array}{l}\text { Crown age } \\
\quad(\mathrm{myr})\end{array}$} \\
\hline & & & Lower & Upper & Median & & \\
\hline \multicolumn{8}{|l|}{ Austral: } \\
\hline Alsodidae & 3 & $36(33)$ & 0 & 3000 & 735 & Temperate & 60.226 \\
\hline Batrachylidae & 4 & $13(5)$ & 0 & 1,821 & 600 & Temperate & 43.136 \\
\hline Ceratophryidae & 3 & $13(6)$ & 0 & 2,394 & 200 & Cerrado & 38.897 \\
\hline Cyclorhamphidae & 3 & $35(9)$ & 0 & 2,740 & 650 & Atlantic Forest & 64.925 \\
\hline Hylodidae & 3 & $42(10)$ & 0 & 2,500 & 900 & Atlantic Forest & 57.383 \\
\hline Odontophrynidae & 3 & $42(26)$ & 0 & 2,500 & 750 & Atlantic Forest & 65.874 \\
\hline Rhinodermatidae & 2 & $3(2)$ & 0 & 1,100 & 250 & Temperate & 61.317 \\
\hline Brachycephalidae & 2 & $61(51)$ & 0 & 2,692 & 800 & Atlantic Forest & 70.786 \\
\hline Bufonidae & 13 & $283(134)$ & 0 & 5,100 & 1,350 & Andes & 72.812 \\
\hline Centrolenidae & 12 & $167(121)$ & 0 & 3,501 & 1,400 & Andes & 33.396 \\
\hline Pristimantinae (Craugastoridae) & 5 & $528(256)$ & 0 & 4,400 & 999 & Andes & 62.258 \\
\hline Dendrobatinae (Dendrobatidae) & 13 & $192(122)$ & 0 & 3,799 & 840 & Andes & 67.352 \\
\hline Aromobatinae (Dendrobatidae) & 5 & $164(114)$ & 0 & 3,300 & 500 & Guiana Shield & 67.184 \\
\hline Hemiphractidae & 6 & $118(86)$ & 0 & 4,600 & 1,640 & Andes & 80.689 \\
\hline Hylinae (Hylidae) & 23 & $537(309)$ & 0 & 3,899 & 585 & Atlantic Forest & 75.777 \\
\hline Phyllomedusinae (Hylidae) & 6 & $54(40)$ & 0 & 1,910 & 638 & Atlantic Forest & 54.784 \\
\hline Leptodactylidae & 14 & $249(181)$ & 0 & 4,480 & 500 & Atlantic Forest & 78.066 \\
\hline Telmatobiidae & 1 & $74(36)$ & 1,001 & 6,000 & 3,325 & Andes & 21.946 \\
\hline
\end{tabular}

Note: Sampled species and number of genera include only those from South America. The table summarizes the results from appendix B, and raw data for elevational distributions are in table S3. The Austral clade aggregates the seven listed families. "Majority region" is the region where the majority of species in the clade occur. 
geographic justification for this. Thus, subdividing these regions would likely pseudoreplicate one or more of the existing data points, at least to some extent.

To determine each species' regional occurrence, we used distribution maps from the GAA (minimum convex polygons) to calculate the number of species present in each region. We assessed each species individually to ensure that it actually occurred in each assigned region (see app. B for details on data quality assessment). We then summed the number of species occurring in each biogeographic region to estimate its richness. We strongly prefer to use distribution maps to infer richness patterns rather than species distribution models (SDM), since the latter approach might predict that species occur in regions where they are actually absent, due to dispersal barriers, species interactions, and other factors that might limit species ranges. SDMs are known to generally overpredict species ranges in amphibians, especially in the Neotropics (Munguía et al. 2012).

To estimate elevational richness patterns in the Tropical Andes, we summed the species present in each band. We used 500-m bands $(0-6,000 \mathrm{~m})$, following standard practice (e.g., Rahbek 1997; Kozak and Wiens 2010b; Hutter et al. 2013). We excluded species from non-Andean montane regions in these estimates.

\section{Diversification Rate Hypothesis}

We estimated diversification rates using a diversity of approaches (apps. C, D), including Bayesian analysis of macroevolutionary mixtures (BAMM 2.5, Nov. 2015; Rabosky 2014), method-of-moments estimators of net rates (Magallón and Sanderson 2001), and the geographic state speciation and extinction (GeoSSE) model (Goldberg et al. 2011). Different approaches gave largely concordant results. In the main text, we present results primarily from BAMM but caution that this approach may have serious issues (Moore et al. 2016). We emphasize that alternative methods generally gave congruent results.

BAMM samples models with differing numbers and types of rate regimes. Rate regimes are areas of the tree sharing the same model parameters (e.g., for diversification rate). BAMM identifies areas of the tree with strong support for a regime shift (significant increases or decreases in rates). We also used BAMM to estimate rates of change in species' elevational midpoint (see below). We estimated rates and the best number of rate shifts and their configurations relative to a null model using Bayes factors scores as selection criteria (see app. C for additional details).

Incomplete phylogenetic taxon sampling may bias some rate estimates, which we address by $(a)$ using a correction for incomplete sampling (\% actual species included), (b) sampling species randomly, and $(c)$ including $>50 \%$ of species from each targeted clade (FitzJohn et al. 2009). However, given that levels of taxon sampling might differ among genera (leading to nonrandom sampling globally), we estimated the sampling fraction for each genus separately. For trait analyses in BAMM, incomplete sampling is not corrected for but should not be problematic if species were sampled randomly with respect to their traits (Rabosky 2014). In support of the assumption of random sampling, the number of species in each elevational zone that were included in the phylogeny was strongly correlated with the total estimated species richness in each zone (Spearman's rank: $r_{\mathrm{s}}=0.979$; $P<.001)$

We tested the diversification rate hypothesis by first estimating mean diversification rates (among species) for each biogeographic region and elevational zone based on the estimated diversification rate for each species (i.e., the rate regime they were assigned to in BAMM). To estimate the overall diversification rate of a region or zone, we calculated the mean rate across all phylogenetically sampled species that occur in each region or elevational zone.

We then used ordinary least squares (OLS) regression in R (ver. 3.1; R Core Team 2016) to test the hypothesis that diversification rates predict species richness among regions and elevational zones. A positive relationship between richness and diversification rates would support the diversification rate hypothesis. For the elevational analyses, we included only family-level Andean clades (see definition below), as the non-Andean clades were typically not distributed across elevations within the Andes. We did not perform a phylogenetic correction here, given that there is no single phylogeny connecting elevational zones and regions.

To further test the robustness of these results, we performed two alternative sets of analyses. First, we directly estimated the net diversification rate for each genus using the clade-based method-of-moments estimator (Magallón and Sanderson 2001) and then estimated mean diversification rates for each region and elevational zone (using 500-m bins). We estimated the rate for each region by assigning each species the clade-based rate for its genus and calculating the mean rate for the region based on the genus-level rate and the number of species in each genus present there. We next found the diversification rate for each elevational zone by calculating the mean of the clade-based rates of all the genera that have a mean elevational distribution within that zone. The mean elevational distribution of a genus was based on the mean of the elevational midpoints of all the species it contained (see app. D for details). We then tested the relationships between mean diversification rates and richness of regions and elevational zones. Second, we used the state-dependent speciation and extinctionbased method, GeoSSE, to calculate geography-dependent speciation and extinction rates for two regions (Andean and lowland; elevational limits defined above) and test for 
a significant difference (Goldberg et al. 2011). Again, these results (app. D) were generally consistent with those from BAMM (but see below).

We also tested whether there was a general relationship between the elevation where clades occurred and their diversification rates (e.g., higher rates at higher elevations). To test the relationship between diversification rates and elevational distributions of genera, we used the mean elevational distribution of each genus as described above. We extracted diversification rates for species from BAMM posterior rate distributions and used the mean across species for each genus. We then found the best-fitting evolutionary model for elevational distributions for the genus-level phylogeny, comparing the white noise, Brownian motion, Ornstein-Uhlenbeck, and $\lambda$ models based on their Akaike information criterion (AIC) values using the function fitContinuous in the $\mathrm{R}$ package geiger (ver. 2.0; Pennell et al. 2014; details in app. C). We transformed the branch lengths of the phylogeny to match that best-fitting model and used phylogenetic generalized least squares (PGLS) regression (Martins and Hansen 1997) to test whether diversification rates of genera are positively related to the occurrence of their species at higher Andean elevations. PGLS regression was performed using the R package ape (ver. 3.0; Paradis et al. 2004).

\section{Time-for-Speciation Hypothesis}

The time-for-speciation hypothesis predicts a positive relationship between current richness of regions and/or habitats and the time elapsed since they were first colonized. We estimated colonization timing for biogeographic regions using the likelihood-based method BioGeoBEARS (Matzke 2013). We constrained dispersal to occur only between adjacent regions (e.g., Andes to Atlantic Forest requires dispersal through Amazonia). In an additional analysis, we also included constraints on the inferred timing of colonization of the Andes to prevent them from being colonized before their first uplift 40 million years ago (full methods in app. E).

To infer the timing of colonization of different elevational bands, we first coded each species with their elevational midpoint. We then found the best-fitting evolutionary model for the data (lowest corrected AIC) on the species-level phylogeny as described above (i.e., Brownian motion, $\lambda$, Ornstein-Uhlenbeck, white noise; using fitContinuous in geiger). We then transformed the branch lengths of the phylogeny to match that best-fitting model and used PGLS ancestral reconstruction in ape to estimate ancestral elevational midpoints across the tree. For these analyses, we assumed that we were estimating the general habitats that ancestral species inhabited rather than their ancestral elevations per se (i.e., montane forests have shifted in elevation over time; Hoorne et al. 2010) and that the organismal traits underlying these distributions are phylogenetically heritable (e.g., physiology, behavioral habitat selection). This latter assumption is supported by the strong phylogenetic signal in species' elevational distributions (for elevational midpoints, Pagel's $\lambda=0.889$ ).

Using these reconstructions, we estimated the timing of the first colonization of each region and elevational band (i.e., the age of the oldest node occurring in a region or 500-m band). We acknowledge that clade ages are rarely known with certainty, but for these analyses we are not interested in the absolute colonization times but rather in the relative times (e.g., whether highland habitats were colonized before lowlands). We then used OLS regression to examine the relationship between current species richness (ln transformed) of each region and elevational band and the time when that region or band was first colonized (additional details in app. E). The use of OLS regression, ln-transformed richness, and the ages of first colonization are all standard approaches for analyses of the time-forspeciation hypothesis (e.g., Hutter et al. 2013).

\section{Species Attractor Hypothesis}

We also tested the species attractor hypothesis as a possible explanation for high Andean species richness. To support the species attractor hypothesis, we would expect to find more dispersal events from the lowlands to the Andes (elevational limits defined above) than vice versa and that more species in the Andes are descended from recent lowland dispersal than vice versa. We first used the biogeographic reconstructions (see above) to estimate dispersal events between the Andes and the lowlands. We considered only dispersal events in the past 40 million years because the Andes did not exist prior to this time (Graham et al. 2009). The dispersal events included were those that resulted in at least one extant species remaining in the region originating from that dispersal event. Finally, we summed the number of extant species on the phylogeny descended from these dispersal events, such that we had a total number of Andean species descended from lowland ancestors and a total number of lowland species descended from Andean ancestors.

We also used GeoSSE (see above and app. C for methods) to calculate dispersal rates between the Andes and lowland regions. To support the species attractor hypothesis, the best-fitting GeoSSE models should have higher dispersal rates from the lowlands to the Andes than vice versa.

\section{Drivers of Andean Speciation}

We also used PGLS to test whether diversification rates of genera are positively related to rates of change in elevational 
distributions, as predicted if Andean speciation was driven by shifts in elevational distributions of Andean taxa. The methods generally followed those described above (see "Diversification Rate Hypothesis"). Rates of diversification and rates of change in elevational midpoints were estimated using BAMM, and the relationship between these variables among genera across Hyloidea and within each family-level clade was tested using PGLS. We also performed these analyses across Hyloidea and within each family-level clade using the method-of-moments estimator to obtain diversification rates for genera, as described above (see app. D for additional details).

The PGLS approach might be problematic if rates from BAMM were significantly autocorrelated due to shared rate regimes among related species; however, this is partially addressed by summarizing rates for genera and not species (Rabosky et al. 2013). Additionally, we also used a permutation test to generate a null distribution of $F$ statistics in $\mathrm{R}$ among genera across Hyloidea. We shuffled rates of change in elevational midpoints among genera and collected $F$-values from PGLS for each of these shuffled data sets. We compared the observed $F$ to the null distribution of $F$ and calculated a $P$ value by finding the percentage of random $F$ values greater than the observed $F$.

\section{Results}

\section{Quantifying Richness Patterns}

South American lowlands (below 900 m) collectively contain 1,583 hyloid species. The Tropical Andes have 1,260 hyloid species (app. B; table S3). The highest elevational richness across all regions is in lowlands from 0 to $500 \mathrm{~m}$, whereas the highest Andean richness is at 1,500-2,000 m (fig. $3 A$ ). Analyses of within-family elevational richness patterns among 10 focal clades (predominantly Andean or lowland) show that five clades (Bufonidae, Centrolenidae, Hemiphractidae, Pristimantinae [subfamily of Craugastoridae], and Telmatobiidae) all have peaks in species richness at midelevations in the Andes (table 1; fig. $3 B$ ). The strong peaks in Pristimantinae and Centrolenidae drive much of Andean midelevation richness, whereas other clades have lower richness and/or weaker peaks. We refer to these five clades hereafter as Andean clades.

\section{Diversification Rate Hypothesis}

Analysis of diversification rates across the phylogeny of South American hyloid frogs using BAMM detected nine significant shifts (eight increases, one decrease) in diversification rates (fig. 2). Five rate increases are located within the five Andean clades: Centrolenidae, Atelopus (Bufonidae), Gastrotheca (Hemiphractidae), Pristimantis (Pristimantinae), and Telmatobius (Telmatobiidae). The remaining three rate increases correspond to (i) colonization of the Atlantic Forest by Rhinella (Bufonidae), (ii) colonization of the Caribbean by Eleutherodactylus (Eleutherodactylidae), and (iii) the base of Hemiphractidae and Terrarana (Brachycephalidae, Ceuthomantidae, Craugastoridae, Eleutherodactylidae). The single rate decrease is found in Cycloramphidae, a small family in the Austral clade from the Atlantic Forest region of southern South America. No shifts corresponded to lowland colonization.

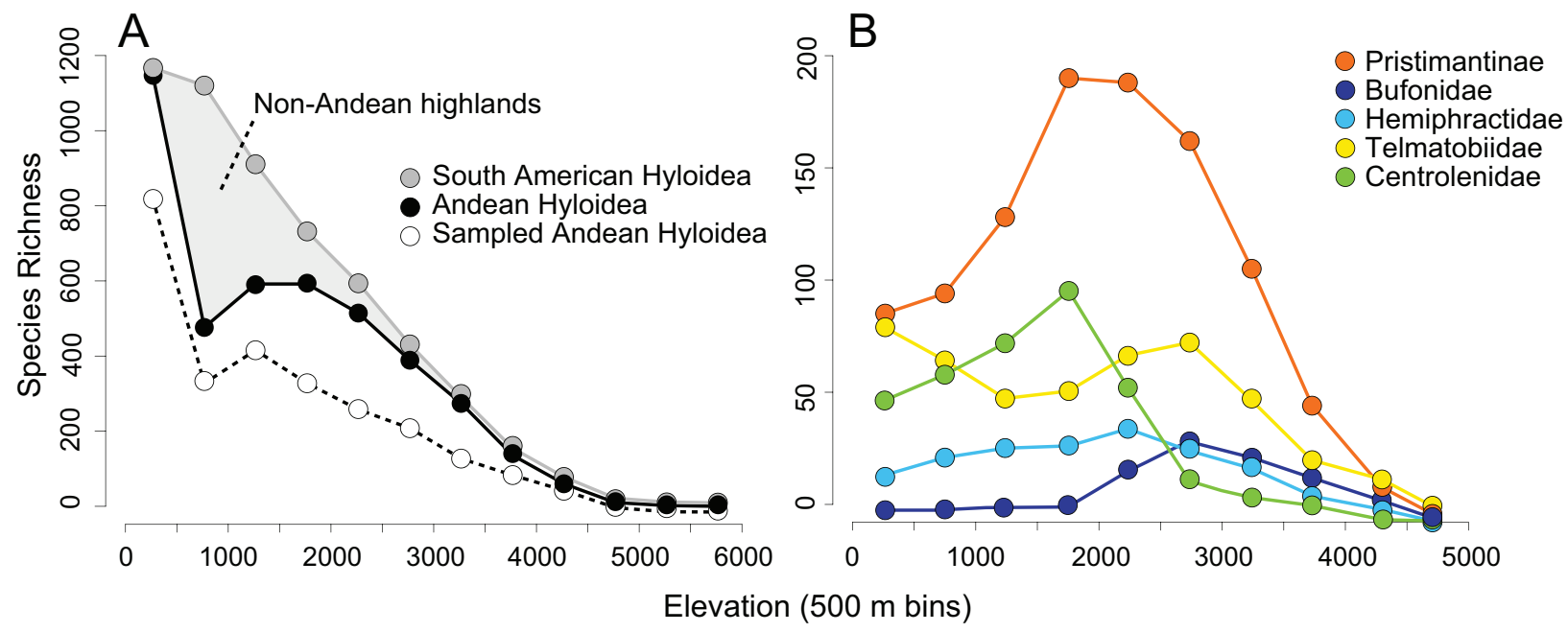

Figure 3: Elevational species richness patterns for South American hyloid frogs $(A)$ and the five major hyloid clades $(B)$ that show a peak in species richness at higher elevations within the Andes. Note that all five of these clades have had a significant increase in diversification rates (see fig. 2). The gray portion of the graph indicates species richness of frogs in higher-elevation habitats outside the Andes (e.g., portions of the Guiana Shield, Atlantic Forest, and temperate South America). 
The Andes have the highest mean diversification rate and the highest species richness among the seven largescale biogeographic regions. Despite this, we did not initially find a significant relationship between mean diversification rates of species within regions and regional species richness, using BAMM-estimated rates and OLS regression ( $n=7$ biogeographic regions; $R^{2}=0.309 ; \quad P=.195$; fig. 4A). However, these results were strongly influenced by a single data point (the Atlantic Forest region), which had low rates and high richness. When that data point was removed, the relationship was extremely strong ( $\left.n=6 ; R^{2}=0.954 ; P<.001\right)$. Conversely, after removing only the Andes the relationship remained nonsignificant and weak $\left(n=6 ; R^{2}=0.107 ; P=.523\right)$. Thus, the Atlantic Forest was apparently an outlier rather than the Andes.
Results were more straightforward using the methodof-moments estimator to estimate diversification rates of genera and regions. We found significant, positive OLS relationships between the diversification rate and current species richness of each region (using $\ln$-transformed rates and richness) for all values of $\varepsilon$ and for both crown-age and stem-age rate estimates $(n=7$ biogeographic regions; $R^{2}=0.819-0.880 ; P=.002-.005$; see app. D for full results). Thus, the unusual results for the Atlantic Forest region may have been an artifact of using BAMM (i.e., Atlantic Forest clades tend to be in low-rate regimes), since the clade-based estimators include all rate differences rather than only significant rate differences (i.e., from BAMM). Overall, these results show that diversification was exceptionally fast in Andean lineages and that this faster diver-
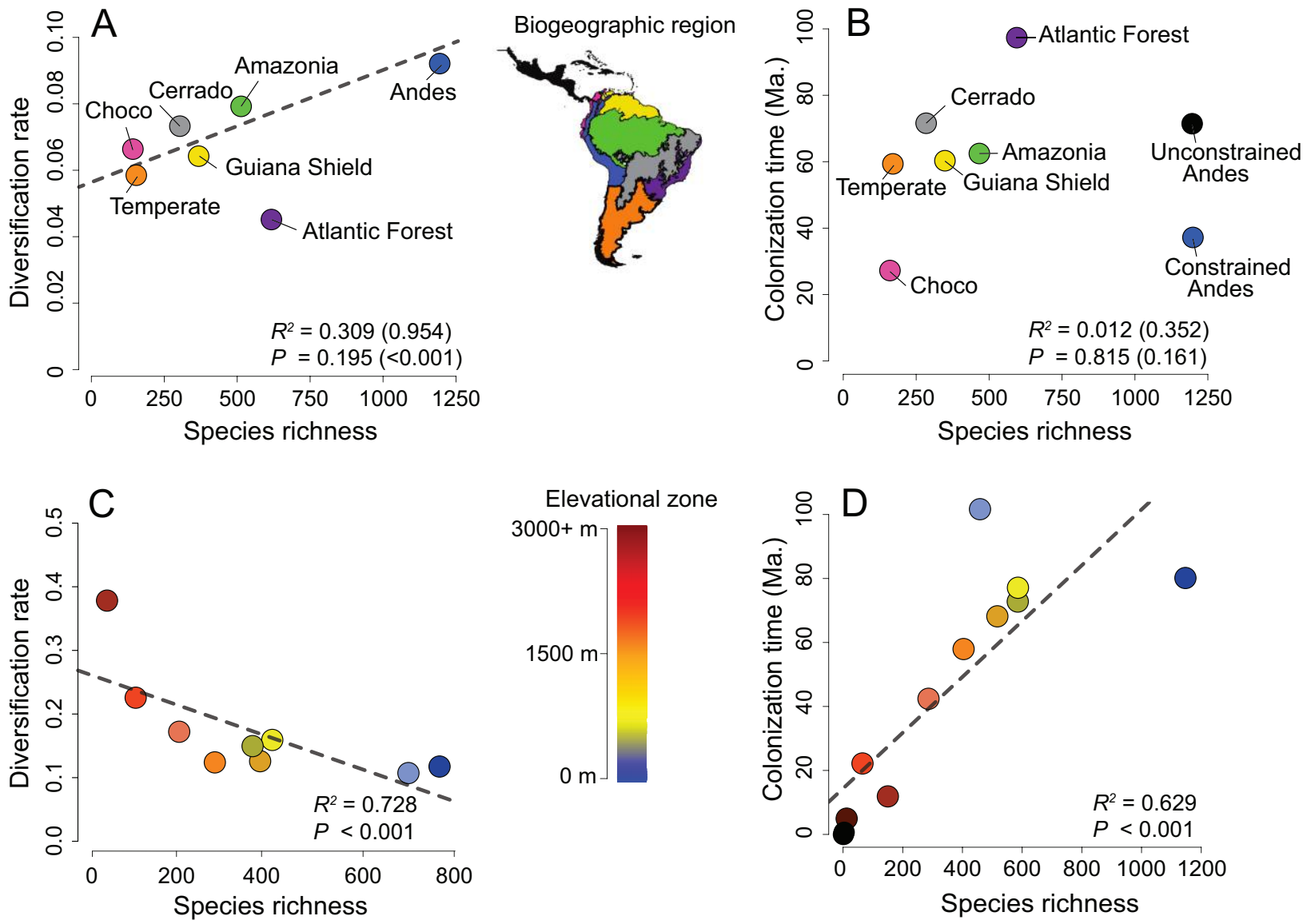

Figure 4: Results for tests of the time-for-speciation and diversification rate hypotheses. $A$, No initial relationship between the species richness and diversification rates of biogeographic regions (from Bayesian analysis of macroevolutionary mixtures) but a strong relationship when the Atlantic Forest outlier is removed (results in parentheses) and when diversification rates are estimated using net diversification rates for clades $\left(R^{2}=0.819-0.880 ; P=.002-.005\right)$. $B$, No relationship between colonization time and species richness of biogeographic regions, regardless of whether the colonization time of the Andes is unconstrained or constrained (unconstrained statistics are in parentheses). $C$, Strong negative relationship between diversification rates and species richness for $500-\mathrm{m}$ elevational zones. $D$, Strong positive relationship between colonization time and species richness of 500-m elevational zones. 
sification rate may help explain the high species richness of the Andes relative to other South American regions.

The two best-fitting models from GeoSSE supported the hypothesis that Andean lineages have higher diversification rates. Speciation rates in the Andes were significantly higher than in lowland South American regions for the best model (Andes: 0.077 species/myr; lowlands: 0.060; species in both regions: 0.019; see app. D for full results with parameter estimates). Extinction rates were lower in the Andes (Andes: 0.003 species/myr; lowlands: 0.006). Thus, net diversification rates (speciation - extinction) were significantly higher in the Andes. Furthermore, the secondbest model $(\Delta \mathrm{AIC}=2.0$ from the optimal model) was nearly the same but with equal extinction rates between regions. Importantly, when comparing the two best models to models in which speciation rates were equal between the Andes and lowlands, the AIC difference was 10 or greater (app. D). Overall, these results further support the hypothesis that increased diversification rates explain high Andean richness.

In contrast, we found that accelerated diversification rates within Andean clades did not explain patterns of elevational species richness within the Andes. We estimated the mean diversification rate of species within each elevational band. Surprisingly, we found a strong negative relationship between the mean diversification rate of species within an elevational band and the band's species richness using OLS regression $\left(n=11 ; R^{2}=0.728 ; P<\right.$ .001 ; fig. $4 C$ ). This result strongly rejects the diversification rate hypothesis for elevational richness patterns within the Andes, given that bands with the lowest richness have the highest rates. Additionally, we tested for a positive relationship between BAMM-estimated diversification rates and current species richness of each 500-m band using OLS regression for each of the 10 smaller-scale focal clades that have species distributed in the Andes. We did not find a significant relationship for most clades tested $\left(R^{2}=0.008-0.145\right.$ $P=.221-.925$; see app. C for full results), except Hemiphractidae $\left(R^{2}=0.689 ; P=.043\right)$. Overall, these results do not support the hypothesis that diversification rates explain family-level Andean richness patterns.

We also tested for a relationship between the current Andean elevational midpoints of genera (excluding non-
Andean montane species) and their BAMM-estimated diversification rates extracted for each genus. The relationship was not significant using PGLS regression $(n=104$; $\left.B_{0}=1,020.5 ; B_{1}=-770.0 ; R^{2}=0.011 ; P=.357\right)$.

\section{Time-for-Speciation Hypothesis}

We found a nonsignificant relationship between colonization time and current richness for the seven regions across South America, using both constrained (i.e., ancestral regions only colonized after they appear) and unconstrained biogeographic reconstructions, respectively $\left(R^{2}=0.012\right.$ and $0.352 ; P=.815$ and .161 ; fig. $4 B$ ). These results further support our conclusion (see above) that patterns of richness among these regions are explained by diversification rates and not by colonization time.

To address the causes of the midelevation peak in Andean richness, we tested for a relationship between colonization time and current species richness of each 500-m band using OLS regression and found a strong, positive relationship $\left(R^{2}=0.629 ; P<.001\right.$; fig. $\left.4 D\right)$. Additionally, we found a positive relationship between richness and colonization times of elevational zones within most lowland $(n=4 / 5)$ and Andean $(n=5 / 5)$ clades tested $\left(R^{2}=0.534-0.927\right.$ $P=.001-.037$; see app. E for full results), except for the predominantly lowland Phyllomedusinae $\left(R^{2}=0.681 ; P=\right.$ .175). Thus, these results support the idea that time generally explains richness patterns at smaller phylogenetic scales and that diversification rates do not (see above). Importantly, all five clades that have Andean richness peaks (see above; fig. 3B) support the time-for-speciation hypothesis within the Andes.

\section{Species Attractor Hypothesis}

The species attractor hypothesis predicts that the Andes are species rich because they are a sink for dispersal from adjacent regions (fig. 1). Our results do not support this hypothesis (table 2). Using likelihood reconstructions of biogeographic regions, we estimate that $\sim 40 \%$ of lowland species are descended from Andean lineages, whereas only $\sim 20 \%$ of Andean species are descended from lowland ancestors (note that the remaining $\sim 80 \%$ of Andean spe-

Table 2: Summary of dispersal between the Andes and lowlands and the contribution of these colonization events to current Andean and lowland species richness testing the species attractor hypothesis

\begin{tabular}{lcccc}
\hline $\begin{array}{l}\text { Type of colonization } \\
\text { event (from-to) }\end{array}$ & $\begin{array}{c}\text { No. colonization } \\
\text { events }\end{array}$ & $\begin{array}{c}\text { Total richness from } \\
\text { colonizations }\end{array}$ & $\begin{array}{c}\text { Proportion of } \\
\text { richness in region }\end{array}$ & $\begin{array}{c}\text { Mean age of colonization } \\
\text { events (myr; SD) }\end{array}$ \\
\hline Andes-Lowlands & 84 & 261 & .40 & $10.7(8.7)$ \\
Lowlands-Andes & 51 & 90 & .20 & $10.2(9.1)$ \\
\hline
\end{tabular}

Note: "Total richness" refers to the total number of species in the colonized region that descended from these colonization events. "Proportion of richness" gives the number of species derived from these colonization events divided by the total number of species in the region. 
cies are descended from older colonization events into the Andes). Additionally, the number of colonization events from the Andes to the lowlands was $~ 40 \%$ higher than those from the lowlands to the Andes (84 events from the Andes to the lowlands; 51 events from the lowlands to the Andes; table 2). These results are also consistent with the dispersal rates between regions (Andes vs. lowlands) estimated by GeoSSE (see app. D), with the dispersal rate from the Andes to the lowlands $\sim 4$ times higher than the rate of dispersal from the lowlands into the Andes (from Andes: 0.019 events/ myr; from lowlands: 0.005 events/myr). Together these results suggest that the Andes have not acted as a species attractor for hyloid frogs.

\section{Drivers of Andean Speciation}

If rapid Andean speciation is caused by changes in elevational distributions of species, then we expect increases in diversification rates in Andean clades to be associated with increases in rates of change in elevational distributions among species in Andean clades. We detected 17 significant increases in rates of evolution for elevational distributions across the entire hyloid tree, with three shifts corresponding to Andean clades: Atelopus (Bufonidae), Pristimantis (Pristimantinae), and Telmatobius (Telmatobiidae; see app. C). Furthermore, we found a significant, positive relationship between rates of change in elevational distributions and diversification rates of genera using PGLS regression $\left(n=102 ; B_{0}=25,124 ; B_{1}=181,388\right.$; $\left.R^{2}=0.032 ; P<.001\right)$. Although the variation in diversification rates that is explained by rates of elevational shifts is small, this significant result is nevertheless supported by permutation tests $(P=.014)$ and by clade-based rate estimation using the method-of-moments estimator (see apps. C, D). Importantly, despite this weak relationship across all families, results within some Andean family-level clades showed strong, significant relationships between diversification rates and rates of change in elevational distributions across many analyses (see apps. C, D for full results). Furthermore, rates of change in elevational distributions explained $>50 \%$ of the variation in diversification rates in the two most important clades driving the Andean midelevation diversity peak (Centrolenidae and Pristimantinae; fig. $3 B$ ). These results support the idea that rapid elevational shifts are associated with at least some of the rapid speciation in Andean lineages.

\section{Discussion}

The Tropical Andes are the most species-rich biodiversity hotspot on Earth (Myers et al. 2000), but the causes of this high biodiversity have remained unclear. Here, we compare the diversification rate and time-for-speciation hy- potheses in hyloid frogs, a group including most South American amphibians. Our results show that the diversification rate and time-for-speciation hypotheses are both important for explaining high Andean richness but at different phylogenetic and spatial scales. We suggest that these scale-dependent patterns may be a widespread but underappreciated property of biodiversity gradients. Our results also have implications for Amazonian richness and speciation mechanisms in the Andes.

\section{Scale-Dependent Causes of Andean Richness Patterns}

Our results show the importance of diversification rates for explaining high Andean species richness at large spatial and temporal scales and the importance of time at smaller scales. The diversification rate hypothesis is supported across South American regions (e.g., the Tropical Andes have the fastest rates and highest richness; fig. 4A) but not at a smaller scale among Andean elevational zones (fig. 4C). Additionally, within most families, diversification rates are also decoupled from elevational richness patterns, showing no significant relationships. At this smaller scale within the Andes, we instead find the highest diversification rates at the highest Andean elevations, which have the lowest species richness (fig. 4C). This pattern might occur for various reasons, such as the absence of other lineages in high-elevation habitats (i.e., rapid speciation due to ecological opportunity) and/or because of recent glaciation within the past $\sim 1-2$ million years driving rapid vicariant speciation (Hooghiemstra and van der Hammen 2004). This latter pattern has also been suggested in other organisms (plants: Hughes and Eastwood 2006; Drummond et al. 2012; birds: Weir 2006; glassfrogs: Hutter et al. 2013). In contrast, the time-for-speciation hypothesis is supported for elevational zones in the Andes (fig. 4D), both among and within families. Even though our results show the importance of diversification rates at large scales, they also illustrate the dangers of considering only diversification rates when addressing the causes of richness patterns and ignoring the effect of time. Our results also illustrate the need to ensure that variation in diversification rates is actually aligned with patterns of species richness.

\section{Species Attractor Hypothesis and Amazonian Diversity}

Our results do not support the species attractor hypothesis (Beckman and Witt 2015; Chazot et al. 2016), the idea that dispersal into the Andes is the main cause of high Andean species richness. Instead, our results for frogs show that the Andes have been an important source of lowland diversity, as suggested previously for dendrobatid poison frogs (Santos et al. 2009) and clearwing butterflies (Elias et al. 2009). Our results suggest that there has been a recent 
influx of Andean clades into western Amazonia, which may offer a partial explanation for the relatively high richness of western Amazonia in many groups of organisms (Hoorn et al. 2010). We also find that most dispersal into western Amazonia occurred within the past 12.4 million years (table 2). These results are also consistent with the hypothesized presence of a large lake system in western Amazonia (Pebas system) created by the Andean uplift and reversal of the Amazon River $\sim 10-23$ million years ago (Shephard et al. 2010; Antonelli and Sanmartín 2011). We speculate that the Pebas system may have acted as a barrier to dispersal between the Andes and Amazonia, and when the lake drained, suitable habitat became available for Andean lineages to colonize western Amazonia. Specifically, the removal of this barrier may explain why so many Andean lineages appear to have colonized western Amazonia over such a brief time period (table 2). These results are in contrast to other studies, which have suggested that speciation occurred in the Pebas system and that taxa then dispersed into the Andes recently (within the past $\sim 15$ million years), increasing Andean richness (Hall 2005; Moonlight et al. 2015; Chazot et al. 2016).

\section{Mechanisms of Andean Speciation}

Our results also address the mechanisms that drive speciation in the Andes. Here, we tested for the first time (to our knowledge) the relationship between diversification rates and rates of change in elevational distributions. We found a general association between bursts of diversification and elevational shifts (fig. 2) and a significant but weak relationship across all hyloids. Most importantly, we found strong relationships between rates of diversification and elevational change within the two most speciesrich, family-level Andean clades (Centrolenidae and Pristimantinae). These results suggest that speciation in the Andes could be partly driven by the rapid Andean uprising (Graham 2009; Parra et al. 2009; Garzione et al. 2014) and lineages shifting elevational distributions, possibly leading to incipient species isolated by occurrence in habitats with divergent climates (e.g., Moritz et al. 2000; Hua and Wiens 2013). Whether these rates of change in elevation distributions correspond directly to changes in species climatic niches remains to be tested for these clades, although this relationship was supported in Andean glassfrogs (Hutter et al. 2013). Our results do not rule out the importance of other mechanisms driving Andean speciation overall, such as allopatric splitting through niche conservatism (as suggested for Andean glassfrogs; Hutter et al. 2013). Nevertheless, our results show that shifts in elevational distribution explain substantial variation in diversification rates within at least two major Andean frog clades.

\section{How Widespread Are the Patterns of Scale Dependence?}

We speculate that the scale-dependent patterns highlighted in our study may be a widespread property of diversity gradients, with patterns at smaller scales explained by time and those at larger scales explained by diversification rates. This idea has been suggested by previous authors (Rabosky 2009; Wiens 2011) and supported by simulations (Pontarp and Wiens 2017) but not explicitly tested empirically. Our results from South American frogs strongly support this idea, with large-scale analyses comparing the Andes to other regions supporting the role of diversification in driving high Andean richness but finer-scale analyses of clades within the Andes supporting the importance of time (fig. 4). This scale dependence could also explain why many studies at smaller phylogenetic scales support time as the explanation for higher montane richness and generally do not support diversification rates (e.g., Wiens et al. 2007; Li et al. 2009; Kozak and Wiens 2010b; Hutter et al. 2013; but see Smith et al. 2007, which supported both time-for-speciation and diversification rates). Studies of other diversity gradients at smaller phylogenetic scales have also supported the importance of time (e.g., aridity gradients in a family of North American lizards; Wiens et al. 2013).

We speculate that this hypothesis of scale dependence may also explain the conflicting results of studies on the latitudinal diversity gradient (Wiens 2011; Pontarp and Wiens 2017), with some studies showing the importance of diversification rates and others supporting the role of time (e.g., Wiens et al. 2006, 2009; Soria-Carrasco and Castresana 2012; Pyron and Wiens 2013; Rolland et al. 2014). For amphibians and mammals, these conflicting results can be explained by differences in phylogenetic scale. In amphibians, studies that support diversification rates span all or most amphibian clades (Wiens 2007; Pyron and Wiens 2013), whereas those supporting time are at smaller phylogenetic scales (e.g., within families: Wiens et al. 2006, 2009). Similarly, analyses across mammals support diversification rates as the major cause of the latitudinal diversity gradient (Rolland et al. 2014), whereas analyses within mammalian genera do not (Soria-Carrasco and Castresana 2012).

The causes of this scale dependence are not yet fully understood. Simulations show that richness will initially be highest in the habitats where a clade originates, even if those habitats do not strongly promote diversification (Pontarp and Wiens 2017). Over time, habitats that strongly promote diversification eventually come to have the highest richness. We suggest that time can be more important for short timescales because the time frame of dispersal could be much shorter than that of speciation. For example, a strong richness gradient could arise from recent dispersal of a single species from high-richness habitats to previously uncolonized habitats, and this could occur over mere de- 
cades. In contrast, differences in richness due to variation in diversification rates may primarily operate under longer timescales because significant lineage accumulation from speciation typically requires much longer periods of time (e.g., tens of millions of years: Wiens et al. 2006, 2007, 2009; Smith et al. 2007; Kozak and Wiens 2010b; Hutter et al. 2013). Additionally, in habitats with low net diversification rates, historical extinction could make it more difficult for species richness to accumulate across longer timescales (Miller and Wiens 2017).

\section{Conclusions}

In summary, our study sheds light on the origins of the exceptional biodiversity of the Tropical Andes relative to other South American regions and on the origins of elevational richness patterns within the Andes. Our results support both the diversification rate and time-for-speciation hypotheses but show that these hypotheses apply at different phylogenetic and geographic scales (diversification rates at larger scales, time at smaller scales). Our study may be the first empirical analysis to directly compare these two hypotheses across different scales. Based on our study (and other simulation and empirical results), we speculate that the dichotomy between the importance of time and diversification rates at different scales might be a widespread phenomenon. A greater appreciation for this scale dependence may help reconcile the conflicting results of many previous studies of richness patterns across clades, habitats, and regions.

\section{Acknowledgments}

We are grateful to two anonymous reviewers and Associate Editor Stephen B. Heard for their suggestions that greatly improved the final work. We thank Ning Ding for assistance in compiling elevational distributions. We thank Dan Rabosky for help with BAMM analysis. We also thank Cole Eskridge for help with phylogeny trait coloration scripting.

\section{Literature Cited}

AmphibiaWeb. 2016. AmphibiaWeb: Information on Amphibian Biology and Conservation. AmphibiaWeb, Berkeley, CA. http:// amphibiaweb.org/. Accessed June 2016.

Antonelli, A., and I. Sanmartín. 2011. Why are there so many plant species in the Neotropics? Taxon 60:403-414.

Beckman, E. J., and C. C. Witt. 2015. Phylogeny and biogeography of the New World siskins and goldfinches: rapid, recent diversification in the Central Andes. Molecular Phvlogenetics and Evolution $87: 28-45$.

Bershaw, J., C. N. Garzione, P. Higgins, B. J. MacFadden, F. Anaya, and H. Alvarenga. 2010. Spatial-temporal changes in Andean pla- teau climate and elevation from stable isotopes of mammal teeth. Earth and Planetary Science Letters 289:530-538.

Chazot, N., K. R. Willmott, F. L. Condamine, D. L. De-Silva, A. V. Freitas, G. Lamas, H. Morlon, et al. 2016. Into the Andes: multiple independent colonizations drive montane diversity in the Neotropical clearwing butterflies Godyridina. Molecular Ecology 25:57655784 .

De Silva, D. L., M. Elias, K. Willmott, J. Mallet, and J. J. Day. 2015. Diversification of clearwing butterflies with the rise of the Andes. Journal of Biogeography 43:44-58.

Drummond, A. J., M. A. Suchard, D. Xie, and A. Rambaut. 2012. Bayesian phylogenetics with BEAUti and the BEAST 1.7. Molecular Biology and Evolution 29:1969-1973.

Drummond, C. S., R. J. Eastwood, S. T. Miotto, and C. E. Hughes. 2012. Multiple continental radiations and correlates of diversification in Lupinus (Leguminosae): testing for key innovation with incomplete taxon sampling. Systematic Biology 61:443-460.

Duellman, W. E. 1999. Distribution patterns of amphibians in South America. Pages 255-328 in W. E Duellman, ed. Patterns of distribution of amphibians, a global perspective. Johns Hopkins University Press, London.

Elias, M., M. Joron, K. Wilmott, K. L. Silva-Brandåo, V. Kaiser, L. M. G. Piñerez, S. Uribe, et al. 2009. Out of the Andes: patterns of diversification in clearwing butterflies. Molecular Ecology 18: 1716-1729.

FitzJohn, R. G. 2012. diversitree: comparative phylogenetic analyses of diversification in R. Methods in Ecology and Evolution 3:10841092.

FitzJohn, R. G., W. P. Maddison, and S. P. Otto. 2009. Estimating trait-dependent speciation and extinction rates from incompletely resolved phylogenies. Systematic Biology 58:595-611.

Garzione, C. N., D. J. Auerbach, J. Jin-Sook Smith, J. J. Rosario, B. H. Passey, T. E. Jordan, and J. M. Eiler. 2014. Clumped isotope evidence for diachronous surface cooling of the Altiplano and pulsed surface uplift of the Central Andes. Earth Planetary Science Letters 393:173-181.

Garzione, C. N., G. D. Hoke, J. C. Libarkin, S. Withers, B. MacFadden, J. Eiler, P. Ghosh, and A. Mulch. 2008. Rise of the Andes. Science 320:1304-1307.

Goldberg, E. E., L. T. Lancaster, and R. H. Ree. 2011. Phylogenetic inference of reciprocal effects between geographic range evolution and diversification. Systematic Biology 60:451-465.

Graham, A. 2009. The Andes: a geological overview from a biological perspective. Annals of the Missouri Botanical Garden 96:371385.

Hall, J. P. W. 2005. Montane speciation patterns in Ithomiola butterflies (Lepidoptera: Riodinidae): are they consistently moving up in the world? Proceedings of the Roval Societv B 272:2457-2466.

Hooghiemstra, H., and T. van der Hammen. 2004. Quaternary Ice Age dynamics in the Colombian Andes: developing an understanding of our legacy. Philosophical Transactions of the Roval Society B 359:173-180.

Hooghiemstra, H., V. M. Wijninga, and A. M. Cleef. 2006. The paleobotanical record of Colombia: implications for biogeography and biodiversity. Annals of the Missouri Botanical Garden 93:297325.

Hoorn, C., F. P. Wesselingh, H. ter Steege, M. A. Bermudez, A. Mora, J. Sevink, I. Sanmartín, and A. Sanchez-Meseguer. 2010. Amazonia through time: Andean uplift, climate change, landscape evolution, and biodiversity. Science 330:927-931. 
Hua, X., and J. J. Wiens. 2013. How does climate influence speciation? American Naturalist 182:1-12.

Hughes, C., and R. Eastwood. 2006. Island radiation on a continental scale: exceptional rates of plant diversification after uplift of the Andes. Proceedings of the National Academv of Sciences of the USA 103:10334-10339.

Hutter, C. R., J. M. Guayasamin, and J. J. Wiens. 2013. Explaining Andean megadiversity: the evolutionary and ecological causes of glassfrog elevational richness patterns. Ecology Letters 16:11351144.

Hutter, C. R., S. M. Lambert, and J. J. Wiens. 2017. Data from: Rapid diversification and time explain amphibian richness at different scales in the Tropical Andes, Earth's most biodiverse hotspot. American Naturalist, Dryad Digital Repository, http://dx.doi.org /10.5061/dryad.1555n.

IUCN Red List. 2014. IUCN Red List of Threatened Species. www.iucnredlist.org. Last accessed February 15, 2015.

Jetz, W., G. H. Thomas, J. B. Joy, K. Hartmann, and A. O. Mooers. 2012. The global diversity of birds in space and time. Nature 491: 444-448.

Kattan, G. H., P. Franco, V. Rojas, and G. Morales. 2004. Biological diversification in a complex region: a spatial analysis of faunistic diversity and biogeography of the Andes of Colombia. Lournal of Biogeography 31:1829-1839.

Kessler, M., S. K. Herzog, J. Fjeldså, and K. Bach. 2001. Species richness and endemism of plant and bird communities along two gradients of elevation, humidity and land use in the Bolivian Andes. Diversity and Distributions 7:61-77.

Kozak, K. H., and J. J. Wiens. 2010a. Accelerated rates of climaticniche evolution underlie rapid species diversification. Ecology Letters 13:1378-1389.

2010b. Niche conservatism drives elevational diversity patterns in Appalachian salamanders. American Naturalist 176:4054.

Li, J., Q. He, X. Hua, J. Zhou, H. Xu, J. Chen, and C. Fu. 2009. Climate and history explain the species richness peak at midelevation for Schizothorax fishes (Cypriniformes: Cyprinidae) distributed in the Tibetan Plateau and its adjacent regions. Global Ecology and Biogeography 18:264-272.

Madriñán, S., A. J. Cortés, and J. E. Richardson. 2013. Páramo is the world's fastest evolving and coolest biodiversity hotspot. Frontiers in Genetics 4:1-7.

Magallón, S., and M. J. Sanderson. 2001. Absolute diversification rates in angiosperm clades. Evolution 55:1762-1780.

Martins, E. P., and T. F. Hansen. 1997. Phylogenies and the comparative method: a general approach to incorporating phylogenetic information into the analysis of interspecific data. American Naturalist 149:646-667.

Matzke, N. J. 2013. Probabilistic historical biogeography: new models for founder-event speciation, imperfect detection, and fossils allow improved accuracy and model-testing. Frontiers of Biogeography 5:242-248.

McGuire J. A., C. C. Witt, J. V. Remsen, A. Corl, D. L. Rabosky, D. L. Altshuler, and R. Dudley 2014. Molecular phylogenetics and the diversification of hummingbirds. Current Biology 24:910-916.

Miller, E. C., and J. J. Wiens. 2017. Extinction and time help drive the marine-terrestrial biodiversity gradient: is the ocean a deathtrap? Ecology Letters 20:911-921.

Moonlight, P. W., J. E. Richardson, M. C. Tebbitt, D. C. Thomas, R. Hollands, C. I. Peng, and M. Hughes. 2015. Continental-scale di- versification patterns in a megadiverse genus: the biogeography of Neotropical Begonia. Journal of Biogeography 42:1137-1149.

Moore, B. R., S. Höhna, M. R. May, B. Rannala, and J. P. Huelsenbeck. 2016. Critically evaluating the theory and performance of Bayesian analysis of macroevolutionary mixtures. Proceedings of the National Academy of Sciences of the USA 113: 9569-9574.

Moritz, C., J. L. Patton, C. J. Schneider, and T. B. Smith. 2000. Diversification of rainforest faunas: an integrated molecular approach. Annual Review of Ecology and Systematics 31:533-563.

Munguía, M., C. Rahbek, T. F. Rangel, J. A. F. Diniz-Filho, and M. B. Araújo. 2012. Equilibrium of global amphibian species distributions with climate. PLoS ONE 7:e34420.

Myers, N., R. A. Mittermeier, C. G. Mittermeier, G. A. B. da Fonseca, and J. Kent. 2000. Biodiversity hotspots for conservation priorities. Nature 403:853-858.

Paradis, E., J. Claude, and K. Strimmer. 2004. ape: analyses of phylogenetics and evolution in $\mathrm{R}$ language. Bioinformatics 20: 289-290.

Parham, J. F., P. C. J. Donoghue, C. J. Bell, T. D. Calway, J. J. Head, P. A. Holroyd, J. G. Inoue, et al. 2012. Best practices for justifying fossil calibrations. Systematic Biology 61:346-359.

Parra, M., A. Mora, C. Jaramillo, M. R. Strecker, E. R. Sobel, L. Quiroz, M. Rueda, and V. Torres. 2009. Orogenic wedge advance in the northern Andes: evidence from the Oligocene-Miocene sedimentary record of the Medina Basin, Eastern Cordillera, Colombia. Geological Society of American Bulletin 121:780-800.

Pontarp, M., and J. J. Wiens. 2017. The origin of species richness patterns along environmental gradients: uniting explanations based on time, diversification rate, and carrying capacity. Iournal of Biogeography 44:722-735.

Pyron, R. A. 2014. Biogeographic analysis reveals ancient continental vicariance and recent oceanic dispersal in amphibians. Systematic Biology 63:779-797.

Pyron, R. A., and J. J. Wiens. 2011. A large-scale phylogeny of Amphibia including over 2,800 species, and a revised classification of extant frogs, salamanders, and caecilians. Molecular Phylogenetics and Evolution 61:543-583.

. 2013. Large-scale phylogenetic analyses reveal the causes of high tropical amphibian diversity. Proceedings of the Roval Societv B 280:20131622.

$\mathrm{R}$ Core Team. 2016. R: a language and environment for statistical computing. Version 3.1. Vienna, Austria.

Rabosky, D. L. 2009. Ecological limits and diversification rate: alternative paradigms to explain the variation in species richness among clades and regions. Ecology Letters 12:735-743.

- 2014. Automatic detection of key innovations, rate shifts, and diversity-dependence on phylogenetic trees. PLoS ONE 9: e89543.

Rabosky, D. L., F. Santini, J. Eastman, S. A. Smith, B. Sidlauskas, J. Chang, and M. E. Alfaro. 2013. Rates of speciation and morphological evolution are correlated across the largest vertebrate radiation. Nature Communications 4:1958.

Rahbek, C. 1997. The relationship among area, elevation, and regional species richness in Neotropical birds. American Naturalist 149:875-902.

Ricklefs, R. E. 1987. Community diversity: relative roles of local and regional processes. Science 235:167-171.

Rolland, J., F. L. Condamine, F. Jiguet, and H. Morlon. 2014. Faster speciation and reduced extinction in the tropics contribute to 
the mammalian latitudinal diversity gradient. PLoS Biology 12 : e1001775.

Rosser, N., A. B. Phillimore, B. Huertas, K. R. Willmott, and J. Mallet. 2012. Testing historical explanations for gradients in species richness in heliconiine butterflies of tropical America. Biological Journal of the Linnean Society 105:479-497.

Santos, J. C., L. A. Coloma, K. Summers, J. P. Caldwell, R. Ree, and D. C. Cannatella. 2009. Amazonian amphibian diversity is primarily derived from late Miocene Andean lineages. PLoS Biology 7: e1000056.

Shephard, G. E., R. D. Müller, L. Liu, and M. Gurnis. 2010. Miocene drainage reversal of the Amazon River driven by plate-mantle interaction. Nature Geoscience 3:870-875.

Smith, S. A., A. Nieto Montes de Oca, T. W. Reeder, and J. J. Wiens. 2007. A phylogenetic perspective on elevational species richness patterns in Middle American treefrogs: why so few species in lowland tropical rainforests? Evolution 61:1188-1207.

Soria-Carrasco, V., and J. Castresana. 2012. Diversification rates and the latitudinal gradient of diversity in mammals. Proceedings of the Roval Society of London B 279:4148-4155.

Stephens, P. R., and J. J. Wiens. 2003. Explaining species richness from continents to communities: the time-for-speciation effect in emydid turtles. American Naturalist 161:112-128.

Weir, J. T. 2006. Divergent timing and patterns of species accumulation in lowland and highland Neotropical birds. Evolution 60:842-855.

Wiens, J. J. 2007. Global patterns of species richness and diversification in amphibians. American Naturalist 170(suppl.):S86-S106.

- 2011. The causes of species richness patterns across space, time, and clades and the role of "ecological limits." Quarterly Review of Biology 86:75-96.

Wiens, J. J., C. H. Graham, D. S. Moen, S. A. Smith, and T. W. Reeder. 2006. Evolutionary and ecological causes of the latitudinal diversity gradient in hylid frogs: treefrog trees unearth the roots of high tropical diversity. American Naturalist 168:579-596.

Wiens, J. J., K. H. Kozak, and N. Silva. 2013. Diversity and niche evolution along aridity gradients in North American lizards (Phrynosomatidae). Evolution 67:1715-1728.

Wiens, J. J., G. Parra-Olea, M. García-París, and D. B. Wake. 2007. Phylogenetic history underlies elevational biodiversity patterns in tropical salamanders. Proceedings of the Roval Society B 274:919-928.

Wiens, J. J., J. Sukumaran, R. A. Pyron, and R. M. Brown. 2009. Evolutionary and biogeographic origins of high tropical diversity in Old World frogs (Ranidae). Evolution 63:1217-1231.

Zheng, Y., and J. J. Wiens. 2015. Do missing data influence the accuracy of divergence-time estimation with BEAST? Molecular Phylogenetics and Evolution 85:41-49.

\section{References Cited Only in the Online Appendixes}

Báez, A. M. 2000. Tertiary anurans from South America. Pages 1388-1401 in H. Heatwole and R. L. Carroll eds. Amphibian biology, vol. 4. Surrey Beatty, Chipping Norton, Australia.

Burnham, K. P., and D. R. Anderson. 1998. Model selection and multimodel inference: a practical information-theoretic approach. Springer, New York.

Evans, S. E., M. E. H. Jones, and D. W. Krause. 2008. A giant frog with South American affinities from the Late Cretaceous of Madagascar. Proceedings of the National Academy of Sciences of the USA 105:2951-2956.
Faivovich, J., L. Nicoli, B. L. Blotto, M. O. Pereyra, D. Baldo, J. S Barrionuevo, M. Fabrezi, E. R. Wild, and C. F. B. Haddad. 2014. Big, bad, and beautiful: phylogenetic relationships of the horned frogs (Anura: Ceratophryidae). South American Journal of Herpetology 9:207-227.

Gradstein, F. M, J. G. Ogg, M. D. Schmitz, and G. Ogg. 2012. The geologic time scale 2012. Elsevier, Boston.

Grant, T., D. R. Frost, J. P. Caldwell, R. Gagliardo, C. F. B. Haddad, P. J. R. Kok, D. B. Means, B. P. Noonan, W. E. Schargel, and W. Wheeler. 2006. Phylogenetic systematics of dart-poison frogs and their relatives (Amphibia: Athesphatanura: Dendrobatidae). Bulletin of the American Museum of Natural History 299:1262.

Harmon, L. J., J. T. Weir, C. D. Brock, R. E. Glor, and W. Challenger. 2008. geiger: investigating evolutionary radiations. Bioinformatics 24:129-131.

Hijmans, R. J. 2012. raster: geographic analysis and modeling with raster data. $\mathrm{R}$ package.

Holman, J. A. 2003. Fossil frogs and toads of North America. Indiana University Press, Bloomington, IN.

Katoh, K., and D. M. Standley. 2013. MAFFT multiple sequence alignment software, version 7: improvements in performance and usability. Molecular Biology and Evolution 30:772-780.

Kearse, M., R. Moir, A. Wilson, S. Stones-Havas, M. Cheung, S. Sturrock, S. Buxton, et al. 2012. Geneious Basic: an integrated and extendable desktop software platform for the organization and analysis of sequence data. Bioinformatics 28:1647-1649.

Kjer, K. M. 1995. Use of rRNA secondary structure in phylogenetic studies to identify homologous positions: an example of alignment and data presentation from the frogs. Molecular Phylogenetics and Evolution 4:314-330.

Kozak, K. H., and J. J. Wiens. 2016. Testing the relationships between diversification, species richness, and trait evolution. Systematic Biology 65:975-988.

Lanfear, R., B. Calcott, S. Y. W. Ho, and S. Guindon. 2012. PartitionFinder: combined selection of partitioning schemes and substitution models for phylogenetic analyses. Molecular Biology and Evolution 29:1695-1701.

Nylander, J. A. A., J. C. Wilgenbusch, D. L. Warren, and D. L. Swofford. 2008. AWTY (are we there yet?): a system for graphical exploration of MCMC convergence in Bayesian phylogenetics. Bioinformatics 24:581-583.

Olson, D. M., E. Dinerstein, E. D. Wikramanayake, N. D. Burgess, G. V. N. Powell, E. C. Underwood, J. A. D'Amico, et al. 2001. Terrestrial ecoregions of the world: a new map of life on Earth. BioScience 51:933-938.

Pagel, M. 1999. Inferring the historical patterns of biological evolution. Nature 401:877.

Pennell, M. W., J. M. Eastman, G. J. Slater, J. W. Brown, J. C. Uyeda, R. G. FitzJohn, M. E. Alfaro, and L. J. Harmon. 2014. geiger v2.0: an expanded suite of methods for fitting macroevolutionary models to phylogenetic trees. Bioinformatics 15:2216-2218.

Plummer, M., N. Best, K. Cowles, and K. Vines. 2016. coda: output analysis and diagnostics for MCMC. R package.

Poinar, G. O., and D. C. Cannatella. 1987. An Upper Eocene frog from the Dominican Republic and its implication for Caribbean biogeography. Science 237:1215-1216.

Price, M. N., P. S. Dehal, and A. P. Arkin. 2010. FastTree 2: approximately maximum-likelihood trees for large alignments. PLoS ONE 5:e9490. 
Rabosky, D. L., M. Grundler, C. Anderson, J. J. Shi, J. W. Brown, H. Huang, and J. G. Larson. 2014. BAMMtools: an R package for the analysis of evolutionary dynamics on phylogenetic trees. Methods in Ecology and Evolution 5:701-707.

Rabosky, D. L., S. C. Donnellan, M. Grundler, and I. J. Lovette. 2014. Analysis and visualization of complex macroevolutionary dynamics: an example from Australian scincid lizards. Svstematic Biology 63:610-627.

Ree, R. H., and S. A. Smith. 2008. Maximum likelihood inference of geographic range evolution by dispersal, local extinction, and cladogenesis. Systematic Biology 57:4-14.

Revell, L. J. 2012. phytools: an R package for phylogenetic comparative biology (and other things). Methods in Ecology and Evolution 3:217-223.

Roček, Z. 2000. Mesozoic anurans. Pages 1295-1331 in H. Heatwole and R. L. Carroll, eds. Amphibian biology, vol. 4. Surrey Beatty, Chipping Norton, Australia.

Rocek, Z., and J. C. Rage. 2000. Tertiary Anura of Europe, Africa, Asia, North America, and Australia. Pages 1332-1387 in H. Heatwole and R. L. Carroll, eds. Amphibian biology, vol. 4. Surrey Beatty, Chipping Norton, Australia.

Roček, Z., M. Wuttke, J. D. Gardner, and B.-A. Singh Bhullar. 2014. The Euro-American genus Eopelobates, and a re-definition of the family Pelobatidae (Amphibia, Anura). Palaeobiodiversity and Palaeoenvironments 94:529-567.

Roelants, K., D. J. Gower, M. Wilkinson, S. P. Loader, S. D. Biju, K. Guillaume, L. Moriau, and F. Bossuyt. 2007. Global patterns of diversification in the history of modern amphibians. Proceedings of the National Academy of Sciences of the USA 104:887-892.

Ruane, S., R. A. Pyron, and F. T. Burbrink. 2010. Phylogenetic relationships of the Cretaceous frog Beelzebufo from Madagascar and the placement of fossil constraints based on temporal and phylogenetic evidence. Journal of Evolutionary Biology 24:274-285.

Sanchiz, F. B. 1998. Encyclopedia of Paleoherpetology. Part 4: Salientia. Dr. Friedrich Pfeil, Munchen, Germany.

Sanmartín, I., and F. Ronquist. 2004. Southern Hemisphere biogeography inferred by event-based models: plant versus animal patterns. Systematic Biology 53:216-243.

Schwarz, G. 1978. Estimating the dimension of a model. Annals of Statistics 6:461-464.

Sullivan, J., D. L. Swofford, and G. Naylor. 1999. The effect of taxon sampling on estimating rate heterogeneity parameters of maximumlikelihood models. Molecular Biology and Evolution 16:1347-1356.

Wiens, J. J. 2011. Re-evolution of lost mandibular teeth in frogs after more than 200 million years, and re-evaluating Dollo's law. Evolution 65:1283-1296.

Wiens, J. J., and M. C. Morrill. 2011. Missing data in phylogenetic analysis: reconciling results from simulations and empirical data Systematic Biology 60:719-731.

Yang, Z. 2006. Computational molecular biology. Oxford University Press, New York.

Associate Editor: Stephen B. Heard Editor: Alice A. Winn

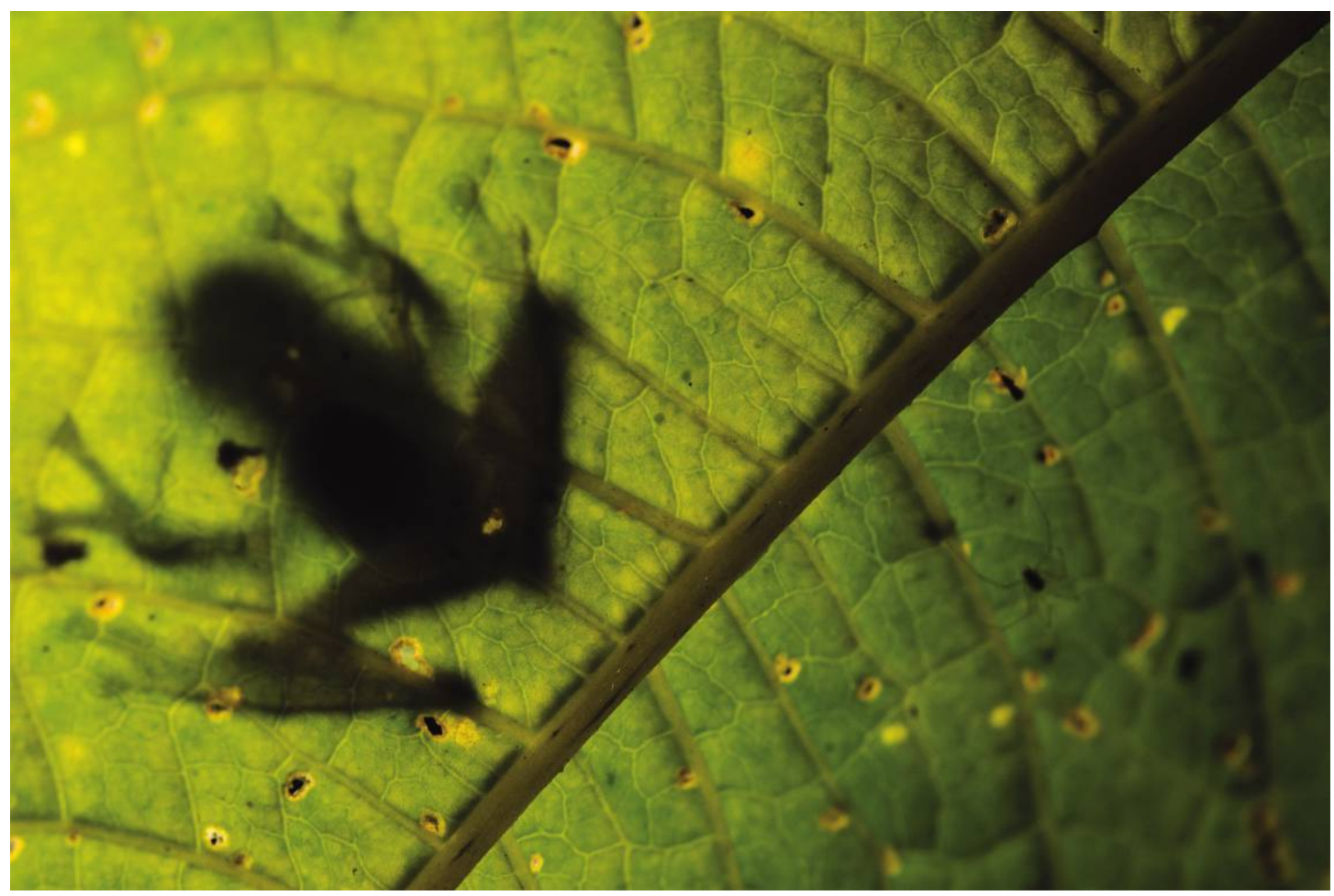

A glassfrog (Centrolenidae) perched on a leaf near a rocky stream in the Tropical Andes of Ecuador. Photo credit: Carl R. Hutter. 